Int. J. Curr. Res. Med. Sci. (2017). 3(7): 38-44

\begin{tabular}{|c|c|c|c|}
\hline International Journal of Current Research in & \\
Medical Sciences & ISSN: 2454-5716 \\
\hline IJCRMS & P-ISJN: A4372-3064, E -ISJN: A4372-3061 \\
WWW.ijcrims.com & \\
\hline
\end{tabular}

\title{
Incidence and Risk Factors of Retinopathy of Prematurity (ROP) in Neonates of Weight 1.5 to $2 \mathrm{~kg}$
}

\author{
Dr SPS Dhillon \\ Assistant Professor, Department of Pediatrics, Govt. Medical College Amritsar, \\ Dr Ashwani Kumar \\ Associate Professor, Department of Pediatrics, Govt. Medical College Amritsar, \\ Dr Astha Rani \\ Junior Resident, Department of Pediatrics, Govt. Medical College Amritsar, \\ Dr Prempal Kaur \\ Associate Professor, Department of Ophthalmology, Govt. Medical College Amritsar, \\ Dr MS Pannu \\ Prof and Head, Department of Pediatrics, Govt. Medical College Amritsar, \\ Corresponding author: Dr Ashwani Kumar \\ Associate Professor, Department of Pediatrics, Govt. Medical College Amritsar, Punjab \\ E-mail : sareen_ashwani@rediffmail.com
}

\section{Abstract}

Objective :- To find incidence and risk factors of ROP in neonates of birth weight $1.5-2 \mathrm{~kg}$.

Methods: - All the neonates admitted in NICU at GMC, Amritsar from August 2014 to July 2015 with birth weight $1.5-2 \mathrm{~kg}$ were enrolled and followed up for all neonatal problems and interventions and screened for ROP by indirect ophthalmoscope at 4 weeks of postnatal age and followed up till retinal vascularization was complete. Neonatal risk factors including diseases and various interventions and treatment given to them were noted and data was analyzed statistically.

Results: - A total of 70 children were screened for ROP, 12 of them were diagnosed with retinopathy of prematurity. Thus, incidence of ROP was $17.1 \%$. 11 of them had stage 1 ROP, 1 had stage 2 ROP with plus disease. On univariate analysis, sepsis and oxygen duration of more than 7 days were significantly associated with development of ROP. None of the risk factor was independent predictor of ROP on logistic regression analysis.

Conclusion: - Neonates with birth weight upto $2 \mathrm{~kg}$ having sepsis and oxygen therapy duration of more than 7 days and having other risk factors should be screened for ROP as they can develop ROP including threshold ROP.

Keywords: Retinopathy, prematurity, sepsis 


\section{Introduction}

Retinopathy of prematurity is a fibro vascular proliferative disorder, affecting the peripheral retinal vasculature in premature infants. It is a preventable cause of childhood blindness. ${ }^{1}$ It was first identified by Terry in 1942 who termed it Retrolental Fibroplasia. The term ROP was coined by Health in 1951. ${ }^{2}$ The control of blindness is given a high priority in WHO Vision 2020 (Right to sight) program. ${ }^{3}$ Globally there are estimated 1.4 million children blind due to any cause. ${ }^{4}$ Retinopathy of prematurity is one of several factors causing childhood blindness. First epidemic was reported in 1940 -1950 in Europe and North America occurring primarily in larger and more mature babies with unmonitored supplemental oxygen being the major risk factor. ${ }^{5}$ At present, in developed countries the majority of babies getting severe ROP weigh less than $1000 \mathrm{~g}$ at birth so the cause of ROP is prematurity rather than unregulated oxygen which is termed a "second epidemic." India, like other middleincome countries is experiencing the 'third epidemic' of blindness due to ROP which is a mixture of the first two epidemics meaning that both premature and relatively mature babies are being affected ${ }^{7}$. The number of babies with ROP in India will be equal to number of babies having ROP in rest of world put together.

Many studies have reported ROP occurring in relatively bigger and more mature babies with birth weight $>1500 \mathrm{gm}$ and GA $>34$ weeks in our country. The population of $1500 \mathrm{gm}$ to 2000 $\mathrm{gm}$ is unique and less well studied in the past in terms of incidence and risk factors for developing ROP in this population. Present study was undertaken to address this issue.

\section{Materials and Methods}

This prospective cohort study was conducted in Neonatal Intensive Care Unit(NICU), Govt. Medical College, Amritsar, on infants with birth weight of $1.5-2 \mathrm{~kg}$ from August 2014 to July
2015. Total one hundred and sixty three neonates of birth weight $1.5-2 \mathrm{~kg}$ were admitted. 93 babies could not be screened due to death, exclusion due to congenital malformations and loss to follow up. 70 infants were followed up as per protocol and included in the study. On admission, babies were examined and managed as per existing medical conditions and as per unit protocol. The babies were weighed at birth, other demographic information obtained and entered in the study questionnaire which included the gender, mode of delivery, neonatal risk factors i.e. birth asphyxia, sepsis, apnea, NEC, HIE, pneumonia, hyperbilirubinemia, seizures, meningitis, HMD and treatment modalities given to babies documented in questionnaire i.e. any use and duration of supplemental oxygen, phototherapy, surfactant, exchange transfusion, blood transfusion, IVF, type of feeding.

Detailed Eye examination of all the babies were conducted by a single ophthalmologist at 4 weeks postnatally. Pupilary dilatation was achieved with a mixture of $2.5 \%$ phenylephrine and $0.5 \%$ tropicamide instilled 3 times before the scheduled examination. Topical anaesthetic $2 \%$ proparacaine was used. The examination protocol included examining the fundus using an indirect ophthalmoscope with $20 \mathrm{D}$ lens or $28 \mathrm{D}$ lens. The retinal findings were documented carefully in examination sheets as per guidelines of ICROP. Follow- up examinations were conducted until full vascularization of retina reached zone 3 or until full remission of ROP after treatment.

Data was analyzed statistically. The incidence rate of ROP was described in simple proportion. By using the chi-squared test, Univariate analysis of risk factors between 2 groups i.e. with and without ROP was done. A logistic regression model was performed and the adjusted OR $(95 \%$ CI) was obtained for the risk factors which had been shown to be significant in univariate analysis. A probability (p) of less than 0.05 was considered significant. 
Int. J. Curr. Res. Med. Sci. (2017). 3(7): 38-44

\section{Results}

In our study, out of 70 neonates, 12 developed ROP as shown in Table no.1.

Table No 1: Incidence of ROP

\begin{tabular}{|c|r|c|}
\hline No. of Neonates & ROP Present & ROP Absent \\
\hline 70 & $12(17.1 \%)$ & $58(82.9 \%)$ \\
\hline
\end{tabular}

The incidence of ROP was $17.1 \%$ and 11 of them were having stage 1 ROP, 1 of them was having stage 2 ROP with plus disease. No one had stage 3 or stage 4 ROP. Out of 12 cases, 11 of them were having regressive ROP, which did not required treatment.
Table no. 2 shows various neonatal diseases as risk factors for ROP. Sepsis was statistically significant risk factor for ROP development on univariate analysis.

Table no.2 : Neonatal diseases as risk factors for ROP

\begin{tabular}{|l|l|c|c|c|}
\hline $\begin{array}{l}\text { S. } \\
\text { No. }\end{array}$ & Risk factors & $\begin{array}{c}\text { ROP } \\
\text { Present(12) }\end{array}$ & $\begin{array}{c}\text { ROP } \\
\text { Absent(58) }\end{array}$ & $\mathrm{x}^{2} \mathrm{p}$ value \\
\hline 1. & Shock & 1 & 5 & 0.974 \\
\hline 2. & PNA & 3 & 17 & 0.764 \\
\hline 3. & Anemia & 3 & 5 & 0.105 \\
\hline 4. & Apnea & 1 & 1 & 0.211 \\
\hline 5. & Sepsis & 5 & 24 & 0.008 \\
\hline 6. & NNJ & 4 & 17 & 0.401 \\
\hline 7. & HMD & 1 & 7 & 0.065 \\
\hline 8. & NEC & 1 & 1 & 0.211 \\
\hline 9. & Pneumonia & 0 & 3 & 0.860 \\
\hline 10. & Hypoglycemia & & & 0.421 \\
\hline
\end{tabular}

Table no. 3 shows comparison of treatment modalities between 2 groups with ROP and without ROP. Although surfactant administration $(\mathrm{OR}=2.545,95 \%$ CI $0.212-30.578 ; \mathrm{p}=0.461$ ), Blood Transfusion ( $\mathrm{OR}=2.625,95 \%$ CI 0.737 - 9.344; $\mathrm{p}=0.136)$, Exchange Transfusion $(\mathrm{OR}=$ $2.545 ; 95 \%$ CI $0.212-30.578 ; \mathrm{p}=0.461)$, Invasive procedures $(\mathrm{OR}=5.182 ; 95 \% \mathrm{CI} \quad 0.301$ $-89.222 ; p=0.257$ ), intravenous fluids (IVF)
$(\mathrm{OR}=4.5 ; 95 \% \mathrm{CI}=0.860-23.547 ; \mathrm{p}=0.075)$, hood oxygen $(\mathrm{OR}=3.286 ; 95 \%$ CI $0.659-$ $16.385, \mathrm{p}=0.147)$ were likely to be associated with development of ROP but association was not significant. This data showed that on univariate analysis oxygen administration for more than 7 days was a statistically significant risk factor for development of ROP. 
Int. J. Curr. Res. Med. Sci. (2017). 3(7): 38-44

Table no.3 Treatment modalities as risk factors for ROP

\begin{tabular}{|c|c|c|c|c|c|}
\hline $\begin{array}{l}\text { S. } \\
\text { NO. }\end{array}$ & \multicolumn{2}{|c|}{ TREATMENT } & $\begin{array}{c}\text { ROP } \\
\text { Present(12) }\end{array}$ & $\begin{array}{c}\text { ROP } \\
\text { Absent(58) }\end{array}$ & $X^{2}$ p value \\
\hline 1 & \multicolumn{2}{|c|}{ Resuscitation } & 2 & 11 & 0.852 \\
\hline 2 & \multicolumn{2}{|c|}{ Phototherapy } & 3 & 19 & 0.598 \\
\hline 3 & \multicolumn{2}{|c|}{ Surfactant } & 1 & 2 & 0.447 \\
\hline 4 & \multicolumn{2}{|c|}{ Blood Transfusion(BT) } & 6 & 16 & 0.128 \\
\hline 5 & \multicolumn{2}{|c|}{ Exchange Transfusion (ET) } & 1 & 2 & 0.447 \\
\hline 6 & \multicolumn{2}{|c|}{ Invasive procedures(UVC) } & 1 & 1 & 0.211 \\
\hline 7. & \multicolumn{2}{|c|}{ Oxygen $>7$ days } & 7 & 8 & 0.001 \\
\hline 8. & \multicolumn{2}{|l|}{ IVF $>7$ days } & 3 & 4 & 0.057 \\
\hline \multirow[t]{3}{*}{9.} & \multirow{3}{*}{$\begin{array}{l}\text { Mode of } \\
\text { delivery of } \\
\text { oxygen }\end{array}$} & Hood & 10 & 35 & 0.130 \\
\hline & & CPAP & 6 & 24 & 0.583 \\
\hline & & Ventilator & 1 & 8 & 0.607 \\
\hline
\end{tabular}

Table no 4 shows logistic regression analysis of risk factors found significant on univariate analysis and found that oxygen duration $>7$ days, sepsis were likely to be associated with ROP but association was not statistically significant $(\mathrm{p}>0.05)$. Thus, they were not independent predictors of development of ROP.

Table no.4 : Logistic regression analysis of risk factors

\begin{tabular}{|l|l|c|c|c|}
\hline S. No. & Risk Factors & $\mathrm{p}$ value & $\begin{array}{c}\text { Adjusted Odd } \\
\text { ratio }\end{array}$ & $\begin{array}{c}\text { Confidence } \\
\text { interval }\end{array}$ \\
\hline 1. & Oxygen $>7$ days & 0.059 & 4.667 & $0.945-23.039$ \\
\hline 2. & Sepsis & 0.228 & 3.187 & $0.484-21.000$ \\
\hline
\end{tabular}

\section{Discussion}

Incidence of ROP varies in different neonatal units. $^{8,9}$ Incidence reported by Jalali et al in babies $<2000 \mathrm{gm}$ and GA <36 weeks was $11 \%$ and by Hungi et al in babies $<2000$ gm and GA $<34$ weeks was $10.2 \%^{10,11}$. Vivekar et al reported incidence as high as $44.9 \%$ in babies with birth weight $>1250 \mathrm{gm}^{12}$. Higher incidence of severe ROP in more mature and bigger babies ( mean birth weight $1488 \mathrm{gm}$ for threshold ROP) has been reported by Shah et $\mathrm{al}^{13}$. Sanghi et al reported aggressive posterior ROP (APROP) in infants more than $1500 \mathrm{gm}$ in our country ${ }^{14}$. Although supplemental oxygen therapy has been considered the main risk factor in the past, several recent studies have suggested a multifactorial basis for ROP development. The risk factors reported in different studies ${ }^{15,16,17}$ are very low birth weight, prolonged mechanical ventilation, repeated blood transfusion, septicemia, hyperoxia/hypoxaemia, hypotension, acidosis, apnea treated by bag and mask ventilation, oxygen duration for more than 7 days, respiratory distress syndrome, anemia, patent ductus arteriosus, phototherapy, type of feeding.

ROP is an emerging child health problem in our country. The incidence of ROP has increased in the last decades because of the increased frequency of premature births relevant to the developments in assisted reproduction techniques and the advances in neonatology that allows a great improvement in survival rate of more immature neonates.

It has a well known variation in the incidence as well as in associated risk factors among centers and among countries, related to difference in case selection, sampling variability and aspects of both obstetric and neonatal clinical practice ${ }^{18}$. Although recent studies have reported increased incidence of ROP in babies $>1.5 \mathrm{~kg}$, most of the studies have not suggested their inclusion in the screening program. 
The incidence of ROP in our study was $17.1 \%$. Our incidence was similar to $19.2 \%$ reported by Hakeem et $\mathrm{al}^{19}, 18.5 \%$ reported by Aggarwal et $\mathrm{al}^{20}$. Similarly Jalali et al and Hungi et al reported incidence of $11 \%$ and $10.5 \%$ respectively ${ }^{10,11}$. Shah et al and Sanghi G et al reported threshold ROP and APROP in infants more than $1500 \mathrm{gm}$ babies respectively ${ }^{13,14}$. The incidence in our study was much lower than $35.1 \%$ reported by Bettegowda et $\mathrm{al}^{21}$ and $47.2 \%$ reported by Adedayo et $\mathrm{al}^{22}$. These differences may be due to differences in gestational age, birth weight, quality of infant survival and health care activities and other related factors such as ethnicity and race, limited sample size, loss to follow up. In our study, out of total ROP (12 cases), we found stage 1 ROP in $11(91.7 \%)$, stage 2 ROP with plus disease in $1(8.3 \%)$. No case was diagnosed with ROP stage 3, 4. Our result was comparable to as reported by Adeodyo et $\mathrm{al}^{22}$ who found $84 \%$ stage $1,12 \%$ stage 2 with no plus disease, $4 \%$ with threshold disease, none had stage 3,4.Out of total ROP cases in our study, $91.7 \%$ were having regressive ROP and recovered without treatment and $8.3 \%$ were having progressive ROP and required laser treatment, which was similar to as reported by Sariyadin et al. ${ }^{23}$

The presence of sepsis in our study was a significant risk factor for ROP on univariate analysis but not an independent predictor of ROP on logistic regression analysis. In the literature, this association has already been described by Shah et $\mathrm{al}^{24}$, Babei et $\mathrm{al}^{25}$, Bassiouny et $\mathrm{al}^{15}$, Bettegowda et $\mathrm{al}^{21}$. Sepsis is frequently accompanied by hypotension, which may impair tissue perfusion and release of angiogenic factors (VEGF, IGF-1) secondary to hypoxic stress resulting in ROP.

In our study, the duration of oxygen administration for more than 7 days was a significant risk factor on univariate analysis for development of ROP and this agreed with Shah et $\mathrm{al}^{24}$, Ikeda et $\mathrm{al}^{26}$.

In our study, the mechanical ventilation and CPAP were non-significant risk factors for ROP and this was in agreement with Hakeem et $\mathrm{al}^{19}$, Abrishami et $\mathrm{al}^{27}$.. However, Shah et $\mathrm{al}^{24}$ in their study observed significant association between mechanical ventilation, CPAP and ROP. In summary different studies have shown some differences in risk factors for ROP.

So in India we are facing third epidemic due to more preterm births, increased survival of preterms, unregulated and unblended oxygen, less awareness in pediatricians about saturation targets, ROP screening and lack of trained ophthalmologists. In India large and more mature babies are being affected due to above reasons and different studies may come with different incidences and different risk factors but we need to screen larger and more mature babies as well. So NNF has recommended screening for babies less than $1750 \mathrm{gm}$ and or $<34$ weeks Gestation. Also babies with gestation of 34-36 ${ }^{6 / 7}$ weeks and who remained sick (sepsis, shock) and received ventilation and prolonged oxygen should also undergo ROP screening. In view of the current scenario RBSK guidelines of 2015 has recommended ROP screening of babies upto 2000 gm, >34 weeks with risk factors and any baby considered at risk by Pediatrician. There should be focus on prevention with target saturation in babies <28 weeks as $90-95 \%$ and in more mature babies in range of $88-93 \%$.

\section{Conclusion}

Hence the study concluded that neonates with birth weight $1.5-2 \mathrm{~kg}$ do develop ROP, which may require treatment. Neonates having sepsis and/or received oxygen for more than 7 days or having other risk factors are at high risk for development of ROP including threshold ROP and APROP. Thus, screening for ROP is also recommended in neonates with birth weight up to $2000 \mathrm{gm}$ and or gestation $>34$ weeks if they were exposed to one or more risk factors. Judicious use of oxygen in low birth weight babies, following the guidelines on target saturations and prevention and effective treatment of sepsis is recommended to avoid the development of ROP so as to reduce the burden of blindness. 


\section{Abbreviations}

ROP:Retinopathy of prematurity

VEGF:Vascular Endothelial Growth Factor

IGF1:Insulin Growth Factor 1

NNF:National Neonatology Forum

CPAP:Continuous Positive Airway Pressure

NEC:Necrotising Enterocolitis

HIE:Hypoxic Ischemic Encephalopathy

WHO:World Health Organisation

HMD:Hyaline Membrane Disease

\section{References}

1. WHO' mission for vision. Afr Health 1998;20:38.

2. Ashton N, Ward B, Serpell G. Effect of oxygen on developing retinal vessels in vivo and in vitro studies. Am J Opthalmol 1966;62:412-35.

3. Gilbert C, Awan H. Blindness in children. BMJ 2003;327:760-61.

4. Gilbert C. New issues in childhood blindness. JCEI-1 2001; 14 (40): 53-6.

5. Sorsby A. The incidence and cause of blindness in England and Wales 1948-1962, Reports on public health and Medical Subjects no 114. London; HMSO,1966.

6.Gilbert C, Rahi J , Eckstein M ,O' Sullivan J , Foster A. Retinopathy of prematurity in middle income countries. Lancet 1997; 350 :12-14.

7.Gilbert C, Fielder A, Gordillo L, Quinn G, Semiglia R, Visintin $\mathrm{P}$ et al. International NOROP Group. Characteristics of infants with severe retinopathy of prematurity in countries with low, moderate, and high levels of development: Implications for screening programs. Pediatrics 2005;115: e518-25.

8. Phan MH, Nguyen PN, Reynolds JD. Incidence and severity of retinopathy of prematurity in Vietnam, a developing middle-income country. J Pediatr Ophthalmol Strabismus 2003;40:20812.

9. Fielder AR, Shaw DE, Robinson J, Ng YK. Natural history of retinopathy of prematurity: A prospective study. Eye (Lond) 1992;6:23342.
10. Jalali S, Matalia J, Hussain A, Anand R. Modification of screening criteria for retinopathy of prematurity in India and other middle-income countries. Am J Opthalmol 2006;141:966-968.

11. Hungi B, Vinekar A, Datti N, Kariyappa P, Braganza S, Chinnaiah $S$ et al. Retinopathy of prematurity in a rural Neonatal Intensive Care Unit in South India-A prospective study.Indian J Pediatr 2012;79:911-15

12. Vinekar A, Dogra MR, Sangtam T, Narang A, Gupta A. Retinopathy of prematurity in Asian Indian babies weighing greater than 1250 grams at birth: Ten-year data from a tertiary care center in a developing country. Indian $\mathbf{J}$ Opthalmol 2007;55:331-336

13. Shah PK, Narendran V, Kalpana N, Gilbert C. Severe retinopathy of prematurity in big babies in India: History repeating itself ? Indian J Pediatr 2009;76:801-804

14. Sanghi G, Dogra MR. Katoch D, Gupta A. Aggressive posterior retinopathy of prematurity in infants $>1500 \mathrm{gm}$ birth weight. Indian J Opthalmol 2014;62:254-7.

15. Bassiouny MR. Risk factors associated with retinopathy of prematurity: A study from Oman. J Trop Pediatr 1996; 42: 355-58.

16. Hammer ME, Mullen PW, Ferguson JG, Pai $\mathrm{S}$, Cosby C, Jackson KL .Logistic analysis of risk factors in acute retinopathy of prematurity. Am J Ophthalmol 1986; 102:1-6.

17.Kumar P, Sankar MJ, Deorari A, Azad R, Chandra P, Aggarwal R et al .Risk factors for severe ROP in preterm low birth weight neonates. Indian J Pediatr.2011 Jul;78(7):812-6

18. Gilbert C, Foster A. Childhood blindness in the context of vision 2020, the Right to Sight. Bulletin of WHO 2001; 79: 227-32.

19. Hakeem AHA Abdel, G.B. Mohmed, M.F. Othman. Retinopathy of Prematurity: A Study of Incidence and Risk Factors in NICU of AlMinya University Hospital in Egypt . J Clin Neonatol 2012 ; 1(2): 76-81.

20.Sonal Agrawal, Jagdeesh Prasad Gupta , Jitendra. Study of Retinopathy of Prematurity in Suburban Population in India. International Journal of Recent Trends in Science And Technology ISSN 2014; 9(3) ; 349-52. 
21. Bettegowda S, Kripail M, Rajiv PK, Koulgi AS. Neonatal Risk factors and retinopathy of prematurity among preterm infants. Int $\mathrm{J}$ Res Health Sci 2014 31; 2(1):146-52.

22. Adedayo O Adio, Rosemary O Ugwu, Chidi G, Nwokocha, Augusta U Eneh. Retinopathy of Prematurity in Port Harcourt, Nigeria .ISRN ophthalmology 2014 ;2014: 1-6. article ID 481527.

23.Sariaydin M, Atlihan F, Calkavur S, Olukman O, Ercan G, Ozturk AT et al. One-year experience in the retinopathy of prematurity: frequency and risk factors, short-term results and follow-up. Int J opthalmol 2011; 4(6):63440.

24. Shah VA, Yeo CL, Ling YL, Ho LY. Incidence, risk factors of retinopathy of prematurity among very low birth weight infants in Singapore. Ann Acad Med Singapore. 2005; 34 : 169-78.

25.Homa Babaei, Mohammad Reza Ansari, Ali Asghar Alipour, Shokofe Ahmadipour, Roya Safari-Faramani and Jafar Vakili. Incidence and Risk Factors for Retinopathy of Prematurity in Very Low Birth Weight Infants in Kermanshah, Iran. World Applied Sciences Journal 2012;18 (5): 600-604.

26. Ikeda H, Kuriyama S. Risk factors for retinopathy of prematurity requiring photocoagulation. Jpn J Opthalmol 2004;48:68-71.

27. Majid Abrishami, Gholam-Ali Maemori, Hassan Boskabadi, Zakiye Yaeghobi, Shahin Mafi-Nejad, Mojtaba Abrishami: Incidence and Risk Factors of Retinopathy of Prematurity in Mashhad, Northeast Iran: Iran Red Cres Med J 2013; 15(3): 229-33.

\begin{tabular}{|c|l|}
\hline \multicolumn{2}{|c|}{ Access this Article in Online } \\
\hline & Website: \\
\hline & www.ijcrims.com \\
\hline Quick Response Code & Subject: \\
\hline
\end{tabular}

How to cite this article:

SPS Dhillon, Astha Rani, Prempal Kaur, MS Pannu. (2017). Incidence and Risk Factors of Retinopathy of Prematurity (ROP) in Neonates of Weight 1.5 to 2 kg. Int. J. Curr. Res. Med. Sci. 3(7): 38-44.

DOI: http://dx.doi.org/10.22192/ijcrms.2017.03.07.006 